\title{
Chronic cough in a hospital population; its relationship to atopy and defects in host defence
}

\author{
H M LEWIS,${ }^{*} \ddagger \mathrm{M}$ HAENEY,, $\mathrm{J}$ JEACOCK,$\dagger$ AND H THOMAS $\dagger$ \\ Departments of *Paediatrics and †Clinical Studies, Trafford General Hospital, $¥$ Royal Manchester Children’s \\ Hospital, and §Hope Hospital, Salford
}

SUMMARY The background and aetiology of chronic cough were investigated by comparing 60 children under 6 years with simple cough, 60 children with asthma, and 60 controls. Both cough and asthma were more common in boys and associated with a history of eczema, chest deformity, and skin reactivity to inhaled allergens, but these findings were more prevalent in asthma than cough. House dust mite sensitivity was found in $34(57 \%)$ children with cough, $45(75 \%)$ with asthma, and six $(10 \%)$ controls. Tests of immunological function showed some high concentrations of IgM in groups with both cough and asthma, but high IgE concentrations, eosinophilia, and lymphocytosis were significant only in asthma. $\operatorname{IgG}_{1}$ and $\mathrm{IgG}_{2}$ concentrations were raised in some children with cough or asthma, but the only low subclass concentrations were of $\mathrm{IgG}_{3}$ observed in the group with cough. Children with simple cough represented a heterogeneous population but many showed evidence of atopy. Major defects of immunity were not observed.

Cough is a symptom of respiratory disease but is not an illness in itself. The most common cause is a self limiting viral infection of the upper respiratory tract which lasts from a few days to two to three weeks. ${ }^{1}$ A persistent or recurrent cough in a young child is a familiar problem in paediatric practice but it can be difficult to determine the aetiology. There may be an identifiable chronic infection, for example, pertussis or tuberculosis, a source of recurrent infections, for example, cystic fibrosis or bronchiectasis, or a history suggesting aspiration. Cough associated with wheeze and dyspnoea generally indicates asthma. ${ }^{2-4}$ In many cases the coughing child suffers from no recognisable disease but complains of a non-productive cough without wheeze that interrupts sleep, disturbs the family and may restrict activity. The cough is frequently resistant to innumerable remedies, which include cough suppressants, decongestants, antibiotics, and inhalations.

Chronic persistent cough has been attributed to ill defined conditions that reflect current opinions rather than medical evidence. The literature cites 'post-nasal drip', enlarged adenoids, 'sinobronchitis', 'chronic bronchitis of childhood', and more recently gastro-oesophageal reflux or recurrent upper respiratory tract infection with impaired immunity. ${ }^{5-12}$ The current trend is to attribute chronic cough to mild or early asthma precipitated by house dust, exercise, or frequent viral infections of the upper respiratory tract. Parents of asthmatic children often recall frequent episodes of cough before the child develops wheeze, and impaired lung function or increased bronchial reactivity have been reported in older children and adults with chronic cough. ${ }^{13-17}$ Exercise or nocturnal cough may be attributed to asthma but there is little direct evidence that cough alone indicates asthma in children too young to cooperate with lung function tests.

This study identifies 60 children under 6 years old with chronic simple cough and compares their medical history, physical findings, immunological indices and skin reactivity to inhaled allergens with 60 children with asthma and 60 children without respiratory symptoms. The purpose was to determine whether children with cough could be distinguished from those with asthma or from children without respiratory symptoms with regard to evidence of atopy or defects in humoral immunity that could predispose to upper respiratory tract infection.

\section{Patients and methods}

In the cough group 60 children up to 6 years of age 
were recruited. They comprised all children referred to a paediatric outpatient clinic with persistent cough (lasting more than two months) or frequent episodes of cough - that is, cough for one week each month during the previous six months. The cough was not associated with audible wheeze and medical advisors had heard no added sounds on ausculation of the chest. Three of the 60 children had been referred initially to the ear, nose, and throat department but cough was their predominant symptom.

In the asthma group 60 children attending outpatients were studied. They were children in whom asthma was defined as cough with wheeze, breathlessness, and bronchospasm during at least two separate episodes over a period exceeding two months. None was taking oral steroids.

Children with abnormal chest radiography (other than hyperinflation and mild bronchial thickening), evidence of systemic disease, and with ill defined wheeze or bronchospasm were excluded from both the cough and asthma groups.

The control group comprised 60 children of similar age recruited from hospitals in the area. They were admitted for routine surgical procedures: circumcision $(n=25)$, hernia $(n=15)$, orchidopexy $(n=5)$, strabismus $(n=4)$, and minor urological procedures $(n=8)$; three were outpatients attending for medical conditions other than those involving the chest (encopresis, enuresis, and feeding problems). Children with a history of frequent respiratory infections and those admitted for ear, nose, and throat surgery were excluded.

The children in the cough and asthma groups were recruited consecutively but the inclusion of control patients was adjusted to obtain a similar sex ratio to those in the cough and asthma groups. Informed verbal consent was obtained from a parent. The study was approved by the ethical committees of each district health authority.

The children in the cough and asthma groups were examined by the consultant paediatrician (HML) who completed a standard proforma, assisted by the research sister (HT). The research sister herself interviewed the parents of control children and completed the questionnaire with the help of the admitting surgical house officer. All children in the study (180) were weighed and measured and the measurements were plotted on centile charts. ${ }^{18}$

Children underwent skin prick tests with eight common inhalent allergen extracts using Merck reagents: house dust mite (Dermatophagoides pteronyssinus), house dust, cat fur, dog fur, grass pollen, tree pollen, mixed feathers, mixed moulds and with histamine and a control solution. All tests were performed by the research sister. A wheal diameter
$3 \mathrm{~mm}$ greater than any control wheal was regarded as positive.

Five $\mathrm{ml}$ of blood was taken for: differential white cell count, total serum immunoglobulins, immunoglobulin G subclasses, classical and alternative complement pathway activity, and opsonisation capacity. Whole blood was transported to the immunology laboratory within two hours where serum was separated and stored at $-70^{\circ} \mathrm{C}$.

\section{LABORATORY METHODS}

Full blood counts were measured on a Coulter $\mathrm{S}$ and a manual differential count estimated on 100 cells. Serum immunoglobins and complement components $\mathrm{C} 3$ and $\mathrm{C} 4$ were measured by rate nephelometry (Beckman Auto ICS). Classical complement pathway activity $\left(\mathrm{CH}_{50}\right)$ was measured by Mayer's $\operatorname{method}^{19}$ and alternative pathway activity by a modification of the method of Platts-Mills and Ishizaka ${ }^{20}$ Immunoglobulin $G$ subclasses $\left(G_{1}-G_{4}\right)$ were measured by single radial immunodiffusion using suitable mouse monoclonal antibodies assigned by an International Union of Immunological Societies/WHO Study (Binding Site Ltd). ${ }^{21}$ The standard used was the UK SPSO1 calibrant (SAS Protein Reference Unit). The sensitivity of the assay ranged from $0.1 \mathrm{~g} / \mathrm{l}$ for $\operatorname{IgG}_{1}$ to $0.05 \mathrm{~g} / 1$ for $\mathrm{IgG}_{4}$.

Results were accepted only if the sum of the four IgG subclasses was within $10 \%$ of the total IgG measured by rate nephelometry. Total IgE was measured by an immunoradiometric assay (Hybritech Tandem R IgE) and opsonisation of saccharomyces cerevisiae by the method of Yamamura, Bolder, and Valdimarsson and expressed as a percentage of a normal human reference serum aliquoted and stored at $-70^{\circ} \mathrm{C} .{ }^{22}$

\section{STATISTICAL METHODS}

Data from cough, asthma, and control groups were presented on three by two contingency tables and analysed using $\chi_{2}^{2}$ (two degrees of freedom), and when results indicated deviation from a null hypothesis $\left(\chi_{2}^{2}<0.05\right)$ each of the three groups was retested against each other using $\chi_{1}^{2}$ (one degree of freedom), with Yates's correction.

The immunological data were tested for a normal distribution using a Kolmogorov-Smirnov test for goodness of fit. Data analysis was based on nonparametric methods because of the skewed distribution of most of the immunological parameters. Mann-Whitney U tests and Kruskal-Wallis one way analysis of variance were used to compare values between the three groups. The effects of age on the data were examined visually by scatter plots and by using Spearman rank correlation coefficients. 
Table 1 Sex and age distribution and medical and social history of children in study

\begin{tabular}{|c|c|c|c|c|}
\hline & $\begin{array}{l}\text { Cough } \\
(n=60)\end{array}$ & $\begin{array}{c}\text { Asthma } \\
(n=60)\end{array}$ & $\begin{array}{l}\text { Control } \\
(n=60)\end{array}$ & Significance \\
\hline No of boys $(\%)$ & $44(73)$ & $42(70)$ & $45(75)$ & \\
\hline No of girls (\%) & $16(27)$ & $18(30)$ & $15(25)$ & \\
\hline Median age (years) & 3.4 & $2 \cdot 7$ & $4 \cdot 2$ & $*$ \\
\hline Age range (years) & $0 \cdot 5-5 \cdot 9$ & $0 \cdot 5-6 \cdot 2$ & $0 \cdot 5-6 \cdot 4$ & \\
\hline No $(\%)$ with history of eczema & $16(27)$ & $27(45)$ & $7(12)$ & * \\
\hline No $(\%)$ with duration of respiratory symptoms $>1$ year & $21(35)$ & $35(58)$ & 0 & $*$ \\
\hline No $(\%)$ with asthma in parent or sibling & $20(33)$ & $23(38)$ & $13(22)$ & \\
\hline No (\%) with smoker in household & $33(55)$ & $33(55)$ & $25(42)$ & \\
\hline No $(\%)$ with single or unemployed parent & $15(25)$ & $13(22)$ & 9 (15) & \\
\hline
\end{tabular}

$*=\mathrm{p}<0.05$ by $\chi_{2}^{2}$.

\section{Results}

SEX AND AGE DISTRIBUTION AND MEDICAL AND SOCIAL HISTORY (TABLE I)

There were more boys than girls in both cough and asthma groups. Controls were significantly older than other children in the study (Kruskal-Wallis analysis of variance: $F=7.33, p=0.001$ ) but this was considered in the statistical analysis. There was a significant increase in a history of eczema in those with asthma compared with controls $\left(\chi_{1}^{2}=14 \cdot 8\right.$, $\mathrm{p}=0.0003)$. Eczema was reported less often with cough than with asthma $\left(\chi_{1}^{2}=3.62, p=0.05\right)$ but more often than in the control group $\left(\chi_{1}^{2}=3.44\right.$, $p=0.06)$. No child with asthma gave a history of possible whooping cough in the previous 12 months $\left(\chi_{2}^{2}=8.06, p=0.018\right)$ but the diagnosis might not be suspected in an asthmatic. In none of the children with cough had pertussis been proved bacteriologically. More children with asthma gave a history of respiratory symptoms exceeding one year than those with simple cough $\left(\chi_{1}^{2}=5 \cdot 66, p=0 \cdot 017\right)$. In the cough and asthma groups there were more children with a family history of asthma, with a smoker in the household, or with an unemployed or single parent, but these findings were prevalent in control families and failed to reach significance.
There were no significant differences between the three groups in the frequency of neonatal respiratory illness, in a history of pneumonia or bronchiolitis in the first year, or of urticarial reactions. Neither the racial origin of the parents nor perception of damp housing could be related to cough or asthma.

\section{PHYSICAL EXAMINATION}

The centiles for height and weight were plotted as a histogram for each group and showed a similar distribution in each. Chest deformity (troughing of the rib cage or sternal bowing) was considered mild or marked in $10 / 60(17 \%)$ in children with cough, $27 / 60(45 \%)$ with asthma, and in none of the controls. Chest deformity was observed in significantly more children in the asthma than in the cough group $\left(\chi_{1}^{2}=8 \cdot 84, p=0 \cdot 003\right)$.

\section{INVESTIGATIONS}

\section{Skin tests}

Significantly more children with asthma or cough reacted positively to skin testing than controls $\left(\chi_{2}^{2}=63 \cdot 3, p<0 \cdot 0001\right)$ and the frequency of reactions was higher in asthma than cough $\left(\chi_{1}^{2}=4 \cdot 03, p=0.04\right)$. Reaction to house dust mite was the single most common sensitivity (table 2).

Table 2 Skin test reactions to inhaled allergens

\begin{tabular}{llll}
\hline & $\begin{array}{l}\text { Cough } \\
(n=60)\end{array}$ & $\begin{array}{c}\text { Asthma } \\
(n=60)\end{array}$ & $\begin{array}{c}\text { Control } \\
(n=60)\end{array}$ \\
\hline No (\%) with one or more positive results & $38(63)$ & $48(80)$ & $6(10)$ \\
No (\%) positive to house dust mite & $34(57)$ & $45(75)$ & $6(10)$ \\
No (\%) with five or more positive reactions & $15(25)$ & $24(40)$ & 0 \\
\hline
\end{tabular}

$*=\mathrm{p}<0.05$ by $\chi_{2}^{2}$.

†Wheal $>3 \mathrm{~mm}$. 
Differential white cell counts

Peripheral white cell counts were analysed in 56 children with cough, 58 with asthma, and in 60 controls. A moderate rise of the lymphocyte count $\left(5 \cdot 0-10 \cdot 0 \times 10^{9} / 1\right)$ was observed in 29 children with asthma compared with 13 with cough and seven controls $\left(\chi^{2}=21 \cdot 17 \mathrm{p}=0 \cdot 0001\right)$ but a count exceeding $10.0 \times 10^{9} / 1$ was found in only two children, both in the cough group. A moderate rise of the eosinophil count $\left(0 \cdot 5-1 \cdot 0 \times 10^{9} / 1\right)$ was observed in 15 children with asthma, five with cough, and in three controls $\left(\chi^{2}=12.51 \mathrm{p}=0.002\right)$. Eosinophil counts exceeding $1.0 \times 10^{9} / 1$ were recorded in only five children with asthma, four with cough, and in one control; this was not significant.

\section{Alternative complement pathway}

There was no significant difference in alternative pathway activity between the three groups and no dependence on age. Activity was low in $3 / 60$ children with cough, 7/60 with asthma, and in $6 / 60$ controls.

Immunoglobin and IgG subclass concentrations and classical complement pathway (60 children in each group)

Only IgG and IgM concentrations (for entire

Table 3 Fifth and 95th centile and median values for immunology in 46 control children aged 3-6 years

\begin{tabular}{|c|c|c|c|}
\hline & 5th Centile & Median & 95th Centile \\
\hline $\operatorname{IgG}(g / l)$ & $<4.45$ & $7 \cdot 5$ & $>10.9$ \\
\hline $\operatorname{IgA}(g / 1)$ & $<0.34$ & 0.66 & $>1 \cdot 12$ \\
\hline $\operatorname{IgM}(g / 1)$ & $<0 \cdot 12$ & $0 \cdot 81$ & $>1 \cdot 29$ \\
\hline $\operatorname{IgE}(\mathrm{kU} / 1)$ & $<1 \cdot 0$ & $16 \cdot 3$ & $>540$ \\
\hline $\operatorname{IgG}_{1}(\mathrm{~g} / \mathrm{l})$ & $<3 \cdot 25$ & $5 \cdot 22$ & $>7 \cdot 4$ \\
\hline $\mathrm{IgG}_{2}(\mathrm{~g} / \mathrm{l})$ & $<0.37$ & 0.99 & $>2.07$ \\
\hline $\mathrm{IgG}_{3}(\mathrm{~g} / \mathrm{l})$ & $<0.18$ & 0.33 & $>0.51$ \\
\hline $\mathrm{IgG}_{4}(\mathrm{~g} / \mathrm{l})$ & $<0.02$ & 0.2 & $>0.84$ \\
\hline $\mathrm{CH}_{50}\left(\mathrm{U} / 10^{3} / \mathrm{l}\right)$ & $<24$ & 36 & $>47$ \\
\hline $\mathrm{C} 3(\mathrm{~g} / \mathrm{l})$. & $<0.65$ & 0.92 & $>1 \cdot 28$ \\
\hline $\mathrm{C} 4(\mathrm{~g} / \mathrm{l})$ & $<0 \cdot 10$ & $0 \cdot 15$ & $>0.22$ \\
\hline $\begin{array}{l}\text { Opsonisation } \\
\text { capacity* }\end{array}$ & $<73$ & $101 \cdot 5$ & $>110$ \\
\hline
\end{tabular}

*\%Laboratory control. population and each group) were consistent with a normal distribution, so suitable non-parametric tests were used in preference to $\log$ transformation. ${ }^{23}$ All serum concentrations except IgM and IgG were highly correlated with age when the whole population was examined (Spearman rank correlation coefficient, $p<0.05$ ). Scatterplots of age against concentration were examined visually and a plateau at 3 years was apparent. Each group was then divided into those under 3 years and those 3 years old or more. When the correlation coefficients were recalculated for children aged 3 years and over the effect of age was not significant for all indices except $\operatorname{IgA}$ and IgE concentrations, which continued to rise; hence only those over 3 years were included in the comparative analysis.

In the age range 3-6.4 years there were 36 children with cough, 28 with asthma, and 46 controls. For all the immunological indices the median, fifth, and 95th centile values were calculated from the control group in order to establish the population's normal range (table 3 ). The cough and asthma groups had significantly higher concentrations of IgM than the control group (Mann-Whitney $\mathrm{U}$ test, $\mathrm{p}=0 \cdot 02$ ).

The IgE levels in the asthma group were much higher than in cough or control groups. In all three groups IgE showed a distribution skewed towards high concentrations. Even in the control group 6/46 children had values of $\mathrm{IgE}$ above a generally accepted upper limit of $100 \mathrm{kU} / \mathrm{l}$. Two of these children had reacted positively to skin testing but the other four had no evidence of atopy. There were no significant differences in the distribution of $\operatorname{IgA}$ and total IgG or IgG subclasses between the three groups, but there was a trend towards high $\operatorname{IgG}_{1}$ concentrations in cough $(p=0.06)$ and high $\mathrm{IgG}_{2}$ concentrations in asthma (Mann-Whitney $U$ test, $p=0.09$ ). In order to identify small subgroups of patients with immunological abnormalities contingency tables were drawn of those children with cough or asthma whose immunological indices fell outside the fifth to 95th centile range established from the control, group (table 4). High $\operatorname{IgG}_{1}$ and

Table 4 Immunological abnormalities in children with asthma and cough, outside the fifth and 95th centile range for controls aged 3-6 years. Results are No (\%)

\begin{tabular}{|c|c|c|c|c|}
\hline & $\begin{array}{l}\text { Cough } \\
(n=36)\end{array}$ & $\begin{array}{l}\text { Asthma } \\
(n=28)\end{array}$ & $\begin{array}{l}\text { Control } \\
(n=46)\end{array}$ & $\begin{array}{l}\text { Significance } \\
\left(\chi_{2}^{2}, p \text { value }\right)\end{array}$ \\
\hline High IgM & $11(31)$ & $8(29)$ & $4(9)$ & $7 \cdot 17,0 \cdot 027$ \\
\hline High IgE & 0 & $8(29)$ & $3(7)$ & $15 \cdot 35,0 \cdot 0008$ \\
\hline High $\operatorname{lgG}_{1}$ & $11(31)$ & $5(18)$ & $3(7)$ & $8 \cdot 17,0 \cdot 017$ \\
\hline High $\mathrm{IgG}_{2}$ & 0 & $5(18)$ & $3(7)$ & $7 \cdot 51,0 \cdot 023$ \\
\hline Low IgG $_{3}$ & $11(31)$ & $2(7)$ & $1(2)$ & $15 \cdot 7,0 \cdot 0007$ \\
\hline
\end{tabular}


$\mathrm{IgG}_{2}$ concentrations were apparent in cough and asthma. Low concentrations of IgG subclasses were observed only for $\mathrm{IgG}_{3}$ and in children with cough but the values were only just below the 5th centile control level, hence this effect was not shown using the Mann-Whitney U test. There were no significant differences between the three groups for $\mathrm{C} 3$ or $\mathrm{C} 4$ concentrations, $\mathrm{CH}_{50}$, or opsonisation capacity using either the Mann-Whitney U test or contingency tables. An abnormality of more than one immunological variable was observed in a few children but the numbers were too small to establish interrelationship. Similarly no correlation could be shown between immunological data and positive skin tests.

\section{Discussion}

Most children with chronic simple cough showed evidence of atopy in their reactions to skin testing and their history of eczema. Cough and asthma were both more common in boys; a male:female ratio exceeding 2.0:1 is comparable with the male preponderance of childhood asthma reported in most western countries and attributed in part to the greater susceptibility of boys to respiratory infections. 2425

This study has not proved that cough in children with atopy but no wheeze is equivalent to cough in asthma. The observation of chest deformity in some children with cough implied chronic airway obstruction but they had no other clinical evidence of bronchoconstriction, and they were too young to cooperate with tests of bronchial reactivity. The cough could be due to IgE mediated hypersensitivity to house dust mite with inflammatory reaction and stimulation of cough receptors in the respiratory tract but little or no bronchoconstriction and therefore no wheeze or breathlessness.

Previous studies have described 'cough variant asthma' but in older children able to perform lung function tests or in younger children who showed a subjective response to bronchodilators. ${ }^{13-17}$ Only in the present study have the features of simple cough been compared with typical asthma or with healthy controls.

There were no features of atopy in about $40 \%$ of children in the cough group. Persistent cough for more than two months excluded most viral infections or pertussis but isolation of micro-organisms was not part of the protocol. Environmental effects-for example, passive smoking and damp housing-might be relevant if measured objectively. ${ }^{26}$ Other factors that could be considered to provoke cough include psychogenic cough ${ }^{27}$ (rarely found below 6 years of age) or inhalation from gastro-oesophageal reflux at night. ${ }^{13}$ Oesophageal pH measurements were not undertaken but none of the children had clinical or radiographic features suggestive of inhalation.

There was no evidence that children with cough or asthma suffered severe deficiencies of immunoglobulins or of IgG subclasses that have recently been. associated with both atopy and recurrent upper respiratory tract infections. ${ }^{12} 28-30$ Slightly low concentrations of $\mathrm{IgG}_{3}$ were found in $31 \%$ of children with cough but many (cough and asthma) showed a rise of immunoglobulins indicative of a stressed but not inadequate immunological system. Below the age of 3 years immunoglobulin values were strongly dependent on age and it was not possible to establish a normal range from the small numbers in the control group. In a much larger population of healthy children, Isaacs $e t$ al reached a similar conclusion and warned against making a diagnosis of partial immunoglobulin deficiency from a single sample. ${ }^{23}$ Defects in complement function and opsonising capacity have been described in children and adults with cough or recurrent respiratory infections, ${ }^{11}{ }^{31}$ but in the present investigation low values were no more frequent than in healthy controls.

There could be some bias in the comparison of immunological data as the controls were from a hospital population of children who were, by selection, free from intercurrent or recurrent infection, unlike a random population sample.

The immunological protocol did not include measurement of salivary $\operatorname{IgA}$, functional antibody response to immunisation, cell mediated immunity, neutrophil function or interferon production. Abnormalities of all these variables have been reported in association with frequent infections and with atopy. ${ }^{8-1028} 32$

This review has shown many similarities between simple cough and asthma, most obviously sensitivity to house dust mite. A prospective study of the cohort of the 60 children with cough is in progress in order to explore precipitating factors and determine whether chronic cough is a minor self limiting symptom or one which heralds the onset of classical asthma.

This study was supported by grants from Lipha Pharmaceuticals Ltd and the North Western Regional Health Authority. We are grateful to the surgical and anaesthetic staff of Trafford General Hospital, the Royal Manchester Children's Hospital, and the Manchester Eye Hospital for their cooperation.

\footnotetext{
References

1 Cloutier MM. The coughing child. Postgrad Med 1983;73: $169-75$.

2 Eigen $\mathrm{H}$. The clinical evaluation of chronic cough. Pediatr Clin North Am 1982;29:67-78.
} 
${ }^{3}$ Mellis CM. Evaluation and treatment of chronic cough in children. Pediatr Clin North Am 1979;26:553-64.

4 Williams HE. Chronic and recurrent cough. Aust Paediatr J 1975;11:1-8.

5 Phelan PD. Post-nasal drip and chronic cough. Lancet 1978;ii: 1309.

6 Smith C. Night cough in children. Lancet 1979;i:732.

7 Stell PM, Pahor AL. Night cough in children. Lancet 1979;i:616.

${ }^{8}$ Isaacs D, Webster ADB, Valman HB. Immunoglobulin levels and function in pre-school children with recurrent respiratory infections. Clin Exp Immunol 1984; 58: 335-40.

9 Isaacs D, Clarke JR, Tyrrell DAJ, Valman HB. Selective infection of lower respiratory tract by respiratory viruses in children with recurrent respiratory tract infections. $\mathrm{Br} \mathrm{Med} \mathrm{J}$ 1982;284:1746-8.

${ }^{10}$ Beard LJ, Maxwell GH, Thong YH. Immunocompetence of children with frequent respiratory infections. Arch Dis Child 1981;56:101-6.

1 Richardson VF, Larcher VF, Price JF. A common congenital immunodeficiency predisposing to infection and atopy in infancy. Arch Dis Child 1983;58:799-802.

12 Morgan C, Levinsky RJ. Clinical significance of IgG subclass deficiency. Arch Dis Child 1988;63:771-3.

13 Cloutier MM, Loughlin GM. Chronic cough in children: a manifestation of airway hyperactivity. Pediatrics 1981;67:6-12.

14 Ellul-Micallef $R$. Effect of terbutaline in chronic 'allergic' cough. Br Med J 1983;287:940-3.

15 Hannaway PJ, Hopper DK. Cough variant asthma in childhood. JAMA 1982;247:206-8.

${ }^{16}$ Konig P. Hidden asthma in childhood. Am J Dis Child 1981;135:1053-5.

17 Spelman R. Chronic or recurrent cough in children: a presentation of asthma? $J R$ Coll Gen Pract 1984;34:221-2.

18 Tanner JM, Whitehouse RM, Takaishi M. Standards from birth to maturity for height, weight, height velocity and weight velocity. British children 1965. Part 1. Arch Dis Child 1966;41: 454-71.

${ }^{19}$ Mayer MM. Complement and complement fixation. In: Kabat EA, Mayer MM, eds. Experimental immunochemistry. 2nd ed. Springfield, Ohio: Thomas, 1961:133.

${ }^{20}$ Platts-Mills TAE, Ishizaka K. Activation of the alternative pathway of human complement by rabbit cells. $J$ Immunol 1974;113:348.

21 Jefferis R, Reimer CB, Skvaril F, et al. Evaluation of monoclonal antibodies having specificity for human IgG subclasses: results of an IUIS/WHO collaborate study. Immunol Lett 1985;10:233-52.

22 Yamamura M, Bolder J, Valdimarsson H. Phagocytosis measured as inhibition of uridine uptake by candida albicans. J Immunol Methods 1977;14:19.

${ }^{23}$ Isaacs D, Altman DG, Tidmarsh CE, Valman HB, Webster ADB. Serum immunoglobulin concentrations in preschool children measured by laser nephelometry: references ranges for IgG, IgA and IgM. J Clin Pathol 1983;36:1193-6.

${ }^{24}$ Gregg I. Epidemiological aspects. In: Clark TJH, Godfrey S, eds. Asthma. London: Chapman and Hall, 1983:242-84.

${ }^{25}$ Lee DA, Winslow NR, Speight ANP, Hey EN. Prevalence and spectrum of asthma in childhood. Br Med J 1983;286:1256-8.

${ }^{26}$ Martin CJ, Platt SD, Hunt SM. Housing conditions and ill health. Br Med J 1987;294:1125-7.

${ }^{27}$ Milner AD. Psychogenic cough in childhood. $\mathrm{Br}$ Med $\mathrm{J}$ 1985;290:1847-8.

${ }^{28}$ French MAH, Harrison G. Systemic antibody deficiency in patients without serum immunoglobulin deficiency or with selective IgA deficiency. Clin Exp Immunol 1984;56:18-22.

${ }^{29}$ Smith TF, Bain RP. IgG subclasses in children with chronic chest symptoms. Monogr Allergy 1986;20:119-27.

${ }^{30}$ Loftus BC, Price JF, Lobo-Yeo A, et al. IgG subclass deficiency in asthma. Arch Dis Child 1988;63:1434-7.

31 Ross SC, Densen P. Complement deficiency states and infection: epidemiology, pathogenesis and consequences of neisserial and other infections in an immune deficiency. Medicine (Baltimore) 63:243-73.

32 Isaacs D, Clarke JR, Tyrrell DAJ, Webster ADB, Valman HB. 8 Deficient production of leucocyte interferon (interferon- $\alpha$ ) in vitro and in vivo in children with recurrent respiratory tract infections. Lancet 1981;ii:950-2.

Correspondence to Dr HM Lewis, Trafford General Hospital, Moorside Road, Davyhulme, Manchester M31 3SL.

Accepted 18 April 1989 